Research Journal of Applied Sciences 13 (12): 701-703, 2018

ISSN: $1815-932 \mathrm{X}$

(C) Medwell Journals, 2018

\title{
Review and Evaluate the Geological Structure Using Gravity Data-Case Study
}

\author{
Asghar Teymoorian and Hamidrezasamadi \\ Hamedan Branch, Islamic Azad University, Hamedan, Iran
}

\begin{abstract}
This study focuses on the study of geological structure and gravity data using fractal techniques in an area of Southern Iran he results are acceptable agreement with geological studies and drilling in the region.
\end{abstract}

Key words: Fractal, geological, echniques, acceptable, agreement, gravity data

\section{INTRODUCTION}

The word fractal is derived from the Latin word 'fructus' which means an irregularly broken and ground rock. It was brought up in 1975 for the first time by Benoit B. Mandelbrot. In recent years, Mandelbrot's Brownian fractional surfaces have attracted a lot of attention because of their noticeable similarity to topography (Mandelbrot, 1967; Goodchild, 1982; Fournier and Fussell, 1982). Observing shapes in the nature it is concluded that Euclidean geometry is not able to state and explain natural complex and apparently irregular shapes. In Euclidean geometry dimension is an integer such as 1-3. As a consequence, Euclidean geometry is able to explain one, two, three and higher dimensional phenomena. The other observation is not to consider dimension of phenomena and events to be integer. In addition, we accept that dimension can be changed continuously from $0-1,1-2,2-3$, etc. For example, if a line is of dimension one and a plate is of dimension two, a dimension between one and two can be attributed to a hundreds-of-times broken line in accordance with intensity of breaks in the figure produced.

Fractal method (variogram): Variogram method is widely used to identify dimension of fractal. Taking a large sample of couples of points (with different positions and distances) along with a profile and calculating the difference among their values, fractal dimension is easily obtained by drawing completely logarithmic graph of variance with respect to distance growth and calculating graph slope. Using this method, optimal density of the area can be achieved.

Geology of area: The considered area lies between longitudes $53^{\circ}$ and $54^{\prime}-54^{\circ}$ and $24^{\prime}$ East and latitude $26^{\circ}$ and $43^{\prime}-26^{\circ}$ and $56^{\prime}$ North. This area is spread out to
Lavaran from the East, to Dehno Maragh and Bahmani from the North, Kalat and Mazra'e Jobran from the West and to Persian Gulf from the South. From a geological point of view and considering partitioning Iran, this under-research area is in Zagros area covering North parts of Bandar Abas to the West of Lengeport. Districts in this area belong to the end of mountains in South West of Zagros which is made up of 2 sub-areas of high Zagros and jagged Zagros. The main difference between these two sub-areas in the related part of Hormozgan Province is mostly of structural differences but taking sequences of stones into account, they do not differ.

Implementation theory of the method in the area: Calculations on the data of complete Bouguer anomaly of the studied area made by surface variogram method are as follows. Firstly, a point in the area with identified longitude and latitude is considered as center and a circle, centered at this point with the largest possible radius to draw is drawn to include data as much as possible. This maximum distance is divided to 30 equal groups. Then, variance of Bouguer data difference for each group is calculated and its logarithm is drawn with respect to logarithm of each group differences (Mark and Aronson, 1984). After investigating the graph, points which are supported by Earth's rigid crust and show fractal feature are selected and then we fit the regression line of least squares with them. The slope of this straight line which satisfies the equation: $\mathrm{y}=\mathrm{mx}+\mathrm{b}$, demonstrates fractal dimension of line show in Fig. 1-4:

$$
\mathrm{E}\left\{\left(\mathrm{Z}_{\mathrm{p}}-\mathrm{Z}_{\mathrm{q}}\right)^{2}\right\}=\mathrm{K}\left(\mathrm{d}_{\mathrm{pq}}\right)^{2 \mathrm{H}}
$$

Where:

$Z_{p}$ and $Z_{q}=$ Surface values in the points $q$ and $p$

$\mathrm{d}_{\mathrm{pq}} \quad=$ Horizontal difference among the points

$\mathrm{H} \quad=3-\mathrm{D}$ 


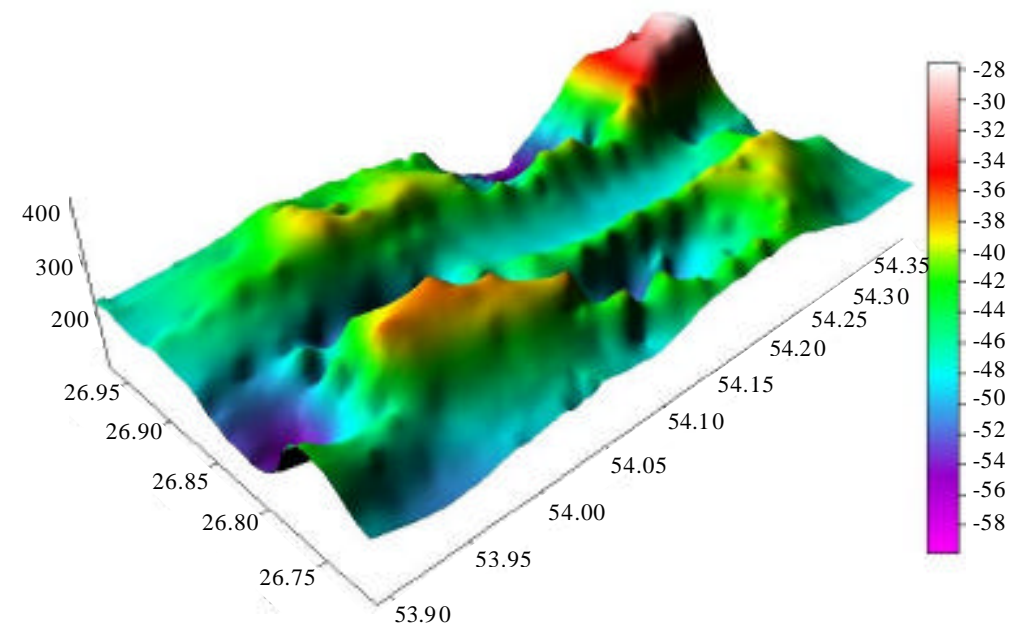

Fig. 1: Complete Bouguer anomaly with density $2.5 \mathrm{~g} / \mathrm{cm}^{3}$

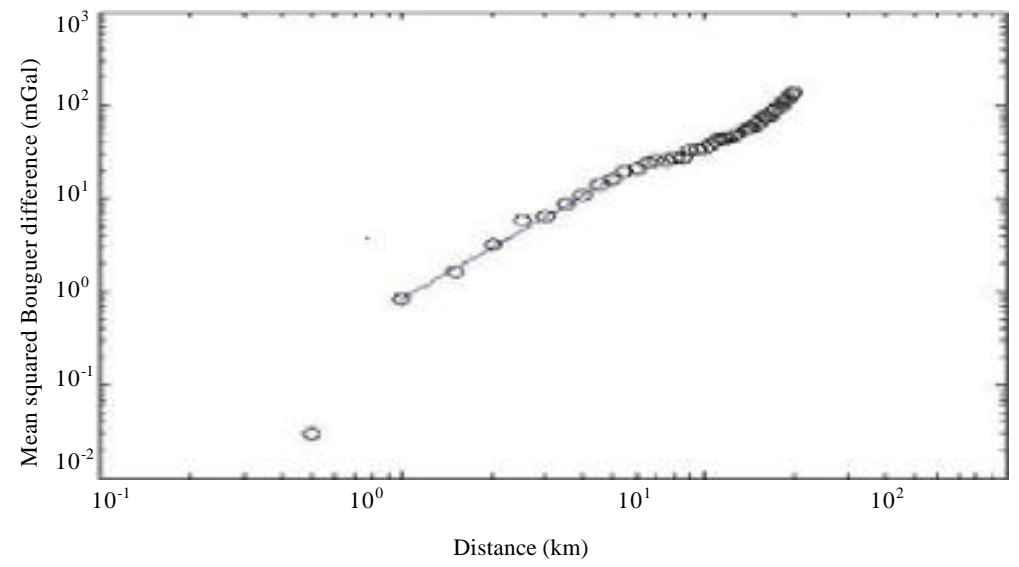

Fig. 2: Complete regression line of Bouguer anomaly of the area with fractal dimension (2.33)

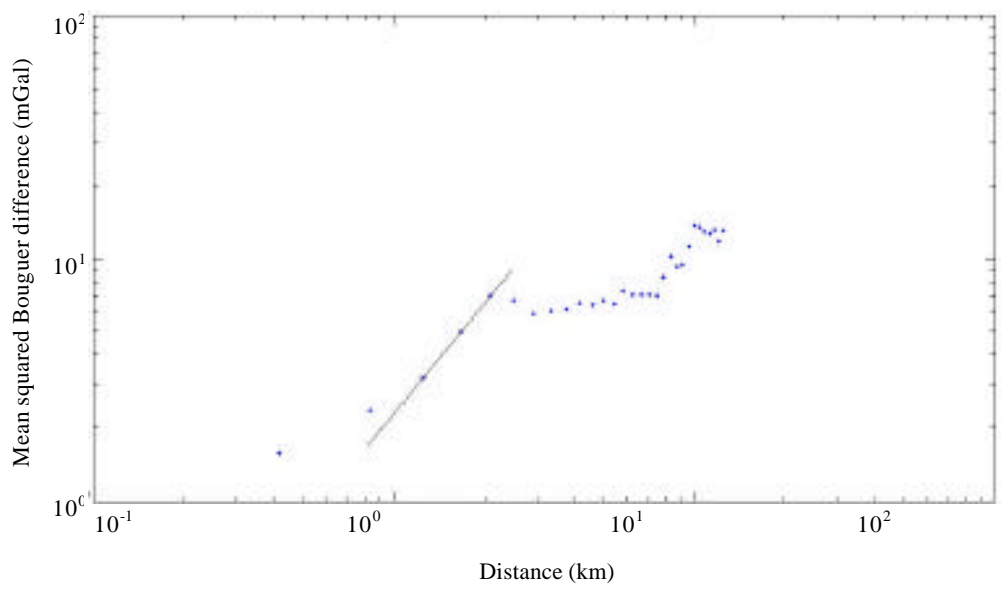

Fig. 3: Complete regression line of Bouguer anomaly of the area with optimal density $\left(2 / 8 \mathrm{~g} / \mathrm{cm}^{3}\right)$ with fractal dimension (2.21) 


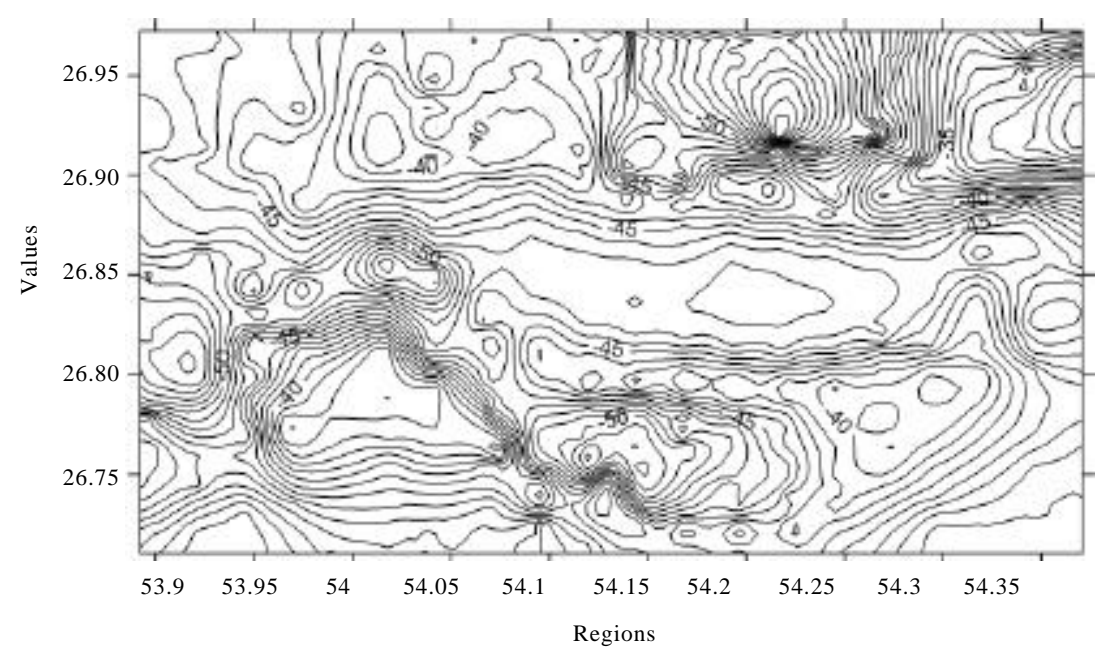

Fig. 4: Contour map. The complete Bouguer anomaly of the region with the density $\left(2.8 \mathrm{~g} / \mathrm{cm}^{3}\right)$ and the balance distance $1 \mathrm{~mm}$ gal by using the variogram's method

Drawing logarithm of variance of differences caused by local complications of the surface with respect to logarithm of distance among the points results in agraph which the existence of a linear relation along the domain implies self-similarity along that domain and its fractal dimension is gained by slope $\mathrm{b}$ of a drawn line in domain point $\mathrm{D}=3-\mathrm{b} / 2$.

Identification scheme of optimal density in the area: In this study, to reduce the dimension of surface roughness of Bouguer anomaly, optimal density is determined and to achieve this goal, firstly, complete data of Bouguer anomaly of the area with different density should be calculated. Then, fractal dimension of each new obtained data series is calculated using mentioned method and draw the results with respect to their density (Thorarinsson and Magnusson, 1988). In the obtained graph, the minimum shown dimension has the best density which is $\left(2 / 8 \mathrm{~g} / \mathrm{cm}^{3}\right)$ for the under-research area shown in Fig. 3 and 4.

\section{CONCLUSION}

Usage of small and large amount of Bouguer density in the Bouguer plate and topography correction makes extra effect of topography on the results of Bouguer anomaly. Supposing that gravitational field has usually less roughness in comparison with topography, we determine Bouguer density with minimizing surface roughness of Bouguer anomaly. The amount of this roughness has been determined by dimension of surface fractal.

In the West of the area (about 53.92, 26.81) the anomaly caused by salty dome in contour map with density of 2.7 is determines more clearly and more definite.
In the North of the area $(54.10,26.95)$ the salty dome in contour with density of 2.8 with respect to contour map with density of 2.3 is more clearly distinguishable.

Windows in Mishan formation (about 54.03, 26.86) which because of erosion caused displacement of Asmari limestone and is distinguishable in the contour map of topography of the area in the contour map of Bouguer anomaly with density of 2.7 is well-represented more clearly.

In the center inclined to the West $(54.03,26.86)$ in the contour map with density of 2.8 a special anomaly can be seen that is likely caused by Barund's fault performance of North East-South West which made formations break and move and made waterway in the valley that cannot be seen in the contour map with density of 2.5 .

\section{REFERENCES}

Fournier, A. and D. fussell, 1982. Computer bendering of stochastic models. Commun. ACM., 25: 371-384.

Goodchild, M.F., 1982. The fractional brownian process as a terrain simulation model. Model. Simul., 13: 1133-1137.

Mandelbrot, B., 1967. How long is the coast of Britain? Statistical self-similarity and fractional dimension. Sci., 156: 636-638.

Mark, D.M. and P.B. Aronson, 1984. Scale-dependent fractal dimensions of topographic surfaces: An empirical investigation, with applications in geomorphology and computer mapping. Math. Geol., 16: 671-683.

Thorarinsson, F. and S.G. Magnusson, 1988. Directional specteral analysis and filtering of geophysical maps. Geophys., 53: 1587-1591. 